\title{
La Ciudad de México en las crónicas de José Joaquín Blanco
}

\author{
Beatriz GARCÍA TORRES \\ Universidad Complutense de Madrid \\ gtorres.beatriz@gmail.com
}

\begin{abstract}
RESUMEN
Este artículo analiza la imagen de la Ciudad de México configurada en la crónica mexicana a partir de los años setenta en especial en los textos de José Joaquín Blanco. Se detiene en el modo en que el género afronta la realidad de una megalópolis que ya solo puede ser asumida de modo fragmentario y múltiple. Entre la utopía y una visión apocalíptica de la ciudad, la crónica reconfigura el espacio y el tiempo urbanos, y formula una nueva identidad crítica gracias a la habilitación de espacios de expresión posibles dentro de las nuevas ciudades modificadas por el capital.
\end{abstract}

Palabras clave: crónica, ciudad, José Joaquín Blanco, México.

\section{Mexico city in José Joaquín Blanco’s chronicles}

\begin{abstract}
The article analyses the image of Mexico City developed in the Mexican chronicle after the seventies, especially in José Joaquín Blanco texts. It focuses on how the genre faces the reality of a megalopolis which can only be conceived in a fragmentary way and from a multiple viewpoint. Between the utopia and an apocalyptic vision of the city, the chronicle reshapes the urban space and time, and formulates a new critical identity by means of adapting possible places for expression inside the new cities modified by capital.
\end{abstract}

Key words: chronicle, city, José Joaquín Blanco, Mexico.

Desde que desembarcaron en tierras americanas los conquistadores españoles hicieron de la fundación de ciudades uno de los instrumentos para la dominación del nuevo espacio (Spitta: 8). Pero la ciudad no es una novedad traída por ellos: la civilización en la que los españoles irrumpen es una civilización urbana. La conquista de México por parte de Cortés sigue un itinerario que conduce al centro del imperio, a la gran Tenochtitlan de la que se escuchan noticias maravillosas. Antes que conocida la ciudad es relatada.

Como si el centralismo del país no dejase escapar a la literatura, la Ciudad de México ha sido descrita, poetizada, narrada desde antiguo disfrutando de un 
protagonismo casi absoluto. Cautivados por la capital, los cronistas le han dedicado innumerables páginas olvidando durante mucho tiempo el resto de la República: en 1980 Carlos Monsiváis comienza el prólogo a su antología de crónicas $A$ ustedes les consta con un apartado que en su título remite a la antigua ciudad: "Homero en Tenochtitlan". Pero también antologías más recientes, como México DF: lecturas para paseantes de Rubén Gallo, se circunscriben al territorio de la capital.

En su libro La ciudad como texto. La crónica urbana de Carlos Monsiváis, Jezreel Salazar anota que los cronistas, a la vez que han dedicado su pluma a reinventar el pasado de la ciudad, "han delineado una ciudad posible. —y añadeAl hablar sobre Gutiérrez Nájera, Monsiváis define la crónica como espacio de la utopía. Desde Bernal Díaz del Castillo, la utopía ha sido un signo y un sino, un rasgo ligado a la crónica de la urbe" (32). Fiel a esta calificación de "espacio de la utopía" la ciudad se ha pretendido emplazamiento del futuro donde la técnica y el progreso hacen posibles adelantos y mejoras: el lugar de la convivencia y el bienestar social.

Pero la utopía no recibe su nombre de forma gratuita y, como tal, el ideal se aleja constantemente de la posibilidad de ubicarse en un espacio de manera efectiva. Las cicatrices del mencionado progreso desdicen la promesa: la ciudad es el peligro, el caos, el amontonamiento, la suciedad, la soledad del individuo perdido en la multitud. El cronista que quiere contar el día a día de la Ciudad de México se encuentra frente a una megalópolis asediada por el tráfico y la creciente inseguridad, consumidora insaciable de recursos y generadora de contaminación ambiental, visual y acústica. Rubén Gallo la llama "desastre urbano", "pesadilla posmoderna" (13) y Juan Villoro habla de "la mujer barbuda" subrayando su atractivo monstruoso.

Por su parte, José Joaquín Blanco insistirá en su naturaleza apocalíptica. Boris Muñoz profundiza en estas ideas de caos, apocalipsis, degradación y catástrofe al hablar de la imagen del DF que configuran los cronistas mexicanos contemporáneos e incide en el estudio de las imágenes escatológicas procedentes tanto de la tradición bíblica apocalíptica como de los mitos de la religión azteca que se ponen en juego. El mito azteca del Quinto Sol contempla cuatro edades a las que sigue una quinta, la nuestra, que finalizará con un terremoto cuyo epicentro será México DF, Tenochtitlan. Esta ciudad apocalíptica es la que a menudo aparece en la crónica contemporánea mexicana en un discurso que anuncia un final catastrófico y se combina con imágenes de los deshechos que abarrotan la ciudad aludiendo al colapso ecológico.

El DF es, según José Joaquín Blanco, una mutación constante que alcanza su fin cada día: "La ciudad de México es el apocalipsis diario. Por todas partes se derrumba, se enfanga, se construye, se vuelve a derrumbar" (1988: 113). La sucesión de verbos y las repeticiones remiten a una historia de demoliciones inacabadas y nuevas edificaciones que nunca terminan de abolir lo anterior. Tanto Blanco como Monsiváis la ven como una ciudad que se renueva en "su incesante 
proceso de destrucción" (Muñoz 2003: 92). De esta manera surge la noción monsivaiana de postapocalipsis: el habitante de la Ciudad de México es el resultado y no la causa de los males. Sobreviviente de un final no definitivo vive en un futuro imposible: el tiempo improbable que hay detrás de la última catástrofe. La idea de postapocalipsis articula una forma de entender la ciudad, establece la metáfora desesperada a través de la cual la urbe se vuelve comprensible.

La crónica se postula como género privilegiado para acercarse a esta megalópolis descentrada que ya solo puede ser asumida de modo fragmentario y que requiere un género híbrido que trasmita la multiplicidad de la materia que trata. Los materiales que acoge, la forma de manejarlos, la cercanía con otros géneros, convierten a la crónica en un objeto extremadamente mutable que se adapta de modo sobresaliente a las nuevas realidades urbanas. Al analizar la prosa de Carlos Monsiváis, Jezreel Salazar escribe: "la crónica resulta ser una alegoría de la ciudad: es fragmentaria, heterogénea, dispersa y caótica. Al sintetizar los rasgos de la metrópoli, la crónica no sólo expresa la imagen de la ciudad en tanto texto (se convierte en un símbolo), sino que configura un espacio público a partir del cual la urbe se vuelve legible" (97). Y añade: "la fragmentación urbana y del espacio público ha traído consigo la fragmentación del discurso y de la conciencia que versa sobre él. Lo que antes llamábamos texto (un discurso terminado, producto de una cultura homogénea) hoy no existe" (98). ${ }^{1}$

La crónica urbana persigue un ideal que se escabulle y, si bien no construye una ciudad utópica habitable, trata, al menos, de reorganizar el caos de la urbe contemporánea. La prosa traza un itinerario, dibuja un mapa que ordena en cierto modo la ciudad en el sentido que Deleuze y Guattari le confieren a la escritura cuando afirman: "Escribir no tiene nada que ver con significar, sino con deslindar, cartografiar, incluso futuros parajes" (12). La escritura perfila la silueta de una ciudad que se expande peligrosamente, que se emborrona y se confunde.

La ciudad actuará como tema y soporte convirtiéndose en territorio de la escritura. Opera como lienzo en el que se dibujan los graffitis políticos y las declaraciones de amor como recoge Blanco en "Las paredes hablan". En sus muros gritan los anuncios de cualquier clase, resuenan reivindicaciones antiguas. ${ }^{2}$ En esta

${ }^{1}$ La crónica es un discurso paradigmático de esta estética de la fragmentación. Las reflexiones de Salazar remiten a las consideraciones de Barthes en El grado cero de la escritura: "Veremos, por ejemplo, que la unidad ideológica de la burguesía produjo una escritura única, y que en los tiempos burgueses (es decir clásicos y románticos), la forma no podía ser desgarrada ya que la conciencia no lo era; y que por lo contrario, a partir del momento en que el escritor dejó de ser testigo universal para transformarse en una conciencia infeliz [...] la escritura clásica estalló y la Literatura en su totalidad, desde Flaubert a nuestros días, se transformó en una problemática del lenguaje" (10).

2 De la crónica mencionada, contenida en Los mexicanos se pintan solos, podemos extraer este ejemplo: "Los muros de la ciudad siempre han sido página colectiva. Sirvió, al 
crónica, Blanco más que describir, lee la ciudad como si de un texto se tratara. Sus páginas de hormigón y asfalto hablan teniendo al cronista por intermediario.

El desplazamiento suele ser la forma elegida por el cronista para reorganizar la ciudad. El traslado vincula unas zonas con otras, las conecta creando un mapa subjetivo. La crónica asume este movimiento y lo utiliza a menudo casos como eje organizador del texto.

Tradicionalmente ese desplazamiento se ha materializado en el paseo. Asediado por el transporte motorizado y la extensión de las nuevas urbes, el flâneur, una de las versiones del cronista testigo, se ha dado por desaparecido en varias ocasiones. A principios del siglo pasado el paseo constituía el modo idóneo de acercarse a la realidad urbana pues permitía observar sin ser notado entre la multitud citadina. ${ }^{3}$ Cuando en Nueva grandeza mexicana, Salvador Novo mostraba a su amigo los encantos de la Ciudad de México el paseo era aún un modo factible de transitar por ella. Aun así, Novo y su compañero ya se sirven del autobús o del tranvía. La diferencia radica en que en aquel momento el motor era percibido como un avance tecnológico positivo y moderno; en la actualidad parece más una penitencia.

Ante el aumento del transporte tanto público como privado, la expansión urbana descontrolada, la construcción de ejes viales que modifican la estructura de la ciudad, fragmentan barriadas e interrumpen comunicaciones, el paseante constata cómo desaparecen los lugares en los que era posible la caminata despreocupada. Sobre todo a partir de los años setenta el peatón se siente marginado dentro de su propio territorio y acosado por los coches y la violencia que estos ejercen en el espacio urbano (como se muestra en la crónica "El automóvil como consolador"). Asumiendo esto, José Joaquín Blanco admite que esta "no es una ciudad para conocerla ni caminarla: es para peserearla, rutacientreparla, trolesangolotearla y metrocruzarla" (1993: 30).

El cronista insiste en su intento de recorrer la ciudad, de labrarla paso a paso aunque sea en pequeñas parcelas, por aquellos lugares donde caminar aún es posible como Coyoacán o el populoso Centro histórico. En "Hacia las Lomas voy, dulce retiro" Blanco se arriesga a pasear por un barrio de clase alta:

día siguiente de la conquista, para un altercado escrito sobre el botín entre Cortés y su tropa: "Tristis est ánima mea/ hasta que la parte non vea", escribieron éstos; "Pared blanca / papel de necios" arguyó él” (Blanco 1990b: 44).

${ }^{3}$ Néstor García Canclini vincula el paseo con la crónica desde principios del siglo XX: "Al narrativizar los segmentos urbanos en la crónica, se construye -mediante lo que Ramos llama "la retórica del paseo"- un orden de la ciudad. La crónica publicada en los periódicos es el medio de comunicación propio de esta modernidad incipiente, donde se enlazan los sentidos parciales de las experiencias urbanas.

Esta tarea se prolonga hasta nuestros días. Desde Salvador Novo a Carlos Monsiváis, José Joaquín Blanco y Herman Bellinghausen se trata de organizar, a través de la crónica periodística, las discontinuidades de la vida urbana". (1995: 97) 
Y que a nadie se le ocurra quedarse hasta tarde a reportear por allá, si no trae coche: al caminar por esas calles de siete leguas, intermitentes patrullas le pedirán identificación y lo someterán a interrogatorios mucho más precisos, quizás, que los que el reportero hubiera querido hacer [...]. (1981: 101)

El cronista retrata a la clase alta mexicana desde las aceras, desde una posición marginal acecha a un grupo que no le incluye. Por eso mismo esta labor solo puede acometerse desde el exterior. ${ }^{4}$ Solo el hecho de pasear por un barrio donde todos están metidos en sus casas y salen a la calle dentro de sus coches convierte al cronista en intruso, en elemento sospechoso. El anonimato del que gozaba el paseante en la ciudad multitudinaria desaparece aquí, cuando el resto permanece aislado. Convertido en cuestionador de la lógica imperante y en símbolo de la perdida habitabilidad de las ciudades, el cronista insiste en acercarse a la sociedad desde la humana altura del paseante. La mayoría de las crónicas donde ejerce este papel de flâneur se encuentran recogidas en Función de medianoche, su primer libro. ${ }^{5}$ La progresiva disminución de las apariciones del cronista paseante podría relacionarse con la creciente dificultad para ejercer ese rol a medida que la ciudad se transforma.

El narrador de Blanco también se mueve por aquellos lugares que la modernidad impone a las nuevas costumbres: los centros comerciales. El centro comercial se convierte en escenario para ver y ser visto, espacio de reunión de jóvenes y de disfrute de familias alrededor del impulso consumista que rige los nuevos ocios como observa en "Plaza Universidad: los árboles darán manzanas en compota" ${ }^{6}$ En

${ }^{4}$ En la crónica mencionada José Joaquín Blanco escribe: "Nuestros ricos siguen soñando en los cuentos de hadas, y se construyen casitas de comics, con sus estatuas y blasones falsificados, techitos de tejas; jardines japoneses y escalinatas relamidas (cuando ya no hay vestidos de cola que arrastrar)." (1981: 100)

5 Algunos ejemplos son: "Mercados sobre ruedas", "Dianética se escribe con D", “Avenida Álvaro Obregón”, “Calle San Juan de Letrán” y "La plaza del metro".

${ }^{6}$ Sería interesante recordar lo que Walter Benjamin anota respecto al París del siglo XIX donde el flâneur se resguarda de la invasión de los carruajes precisamente en los pasajes: galerías comerciales que unían varios edificios (71). Parece que la vinculación del flâneur con el mercado no es tan reciente como podría pensarse sino que este "explorador del capitalismo, enviado al reino del consumidor" (431) encuentra en los espacios del consumo su hábitat desde hace más de un siglo.

Benjamin vislumbró este paso del flâneur de las calles a los grandes almacenes (y de ahí a los enormes centros comerciales): "El flâneur está aún en el umbral, tanto de la gran ciudad como de la clase burguesa. Ninguna de las dos ha podido con él todavía. En ninguna de ellas se siente en casa. Busca su asilo en la multitud. [...] Con la multitud, la ciudad tan pronto es paisaje como habitación. Cosas ambas construidas luego por el gran almacén, que aprovecha 
"Plaza Satélite" se aventura en el centro comercial del mismo nombre abandonando el corazón de la ciudad. ${ }^{7}$ Desde el inicio, el cronista marca distancia respecto al lugar que va a visitar y a la gente que lo frecuenta reivindicando su personalidad frente a ellos. En su viaje hacia Plaza Satélite ensaya el prejuicio que poco después se verá superado por la realidad.

Creía prever esta crónica: durante el trayecto casi la había redondeado mentalmente; una diatriba contra el consumo, centrada en un lugar tan obvio que no requiere el insulto: basta el registro objetivo de algunos de sus detalles -ser una cámara, a la Isherwood. (1981: 85)

El cronista se burla de las pretensiones, el engreimiento y la pretendida perfección del espacio y de quienes se mueven en él hasta que a la crítica sobreviene la gris decepción. La crónica no será agresiva sino que, consciente de su debilidad, recoge el desencanto de quien corrobora que no es uno mismo el que se aleja de los otros sino que son precisamente los otros quienes lo expulsan. El texto muestra la evolución interna del narrador confirmando la idea de que el cronista, al trabajar con la experiencia, no establece verdades inamovibles o apriorísticas sino que se deja modificar por la realidad que retrata.

Ante la reducción creciente del territorio permitido al paseante el trasporte público se posiciona como uno de los lugares fundamentales de la crónica de la ciudad. La urbe moderna pierde lugares de reunión en favor de espacios de cruce y circulación. Estos espacios de tránsito, como el pesero o el metro, aparecen como el lugar de trabajo, del ligue, de las compras y el ocio, el sitio donde se lee, se escucha música o se conversa. No es casual que la mencionada antología México DF: Lecturas para paseantes dedique todo un apartado a textos que otorgan el protagonismo al transporte. ${ }^{8}$

En "Informe sobre camiones" José Joaquín Blanco dedica su prosa al autobús. La investigación requerida será la de la vida diaria. A partir de ahí recoge las voces de los pasajeros y reseña sus peculiaridades: los adolescentes, los novios, las

la misma flânerie para la venta de mercancías. El gran almacén es el último gran territorio del flâneur" (45).

7 "A la experiencia del tránsito urbano moderno cuya fuerza centrípeta se asociaba con el centro de la ciudad, le sucede ahora la dispersión de las coordenadas geográficas y simbólicas del espacio cultural. Para Sarlo, el auge de los centros comerciales o shoppings marca un cambio." (Bencomo 2002: 38)

${ }^{8}$ En el apartado "III. Transportes" de esta antología se incluyen las siguientes crónicas: "La ciudad es el cielo del metro" de Juan Villoro, "Viaje al centro de la ciudad" de Ricardo Garibay, "Metro Insurgentes" de José Joaquín Blanco, "El metro: viaje hacia el fin del apretujón” de Carlos Monsiváis, "Viajar en camión” y "¡Servicios!” ambas de Jorge Ibargüengoitia. 
señoras de clase media... Para su retrato juega un papel protagónico el oído y la captación de la oralidad, característicos de la crónica.

Pero sin duda el transporte estrella será el metro. Blanco escribe "El metro de los suicidas" en Álbum de pesadillas mexicanas a propósito del aumento del número de suicidios en especial en la estación de Centro Médico. Símbolo de la modernidad, escaparate de publicidades y orgullo de la ciudad que provee de transporte barato y eficaz a sus habitantes, el metro acaba convirtiéndose en el lugar elegido para abandonar una vida que esa misma modernidad (desigual) ha convertido en miserable.

Una visión más positiva encontramos en la crónica "Los misterios del metro" contenida en Los mexicanos se pintan solos. En este texto el metro será "guarida" de las clases bajas, "hogar subterráneo de la juventud desempleada, semiexpulsada y mortalmente aburrida de sus hogares" (73). Será entonces una especie de ciudad subterránea más barata, menos vigilada (porque no hay nada que vigilar) pero en cierta manera más libre, más desahogada que la ciudad de arriba, que la teme.

En el nuevo urbanismo que detesta la vida de la calle, de las plazas y los parques, y aspira solamente al invernadero vecinal, comercial u oficinesco de los malls, o de las torres de conjuntos habitacionales y burocráticos, el metro es la nueva calle.

Ahí triunfa la gente que camina. (73)

En 1999 se publica Ciudad de México. Espejos del siglo XX donde Blanco prologa una colección de antiguas fotografías pertenecientes al Fondo Casasola y al Fondo Nacho López en su mayoría. ${ }^{10}$ Comienza su prólogo de esta manera:

Precisamente cuando la fotografía, en su afán de eternizar escenas, se consolida y populariza, las imágenes de la realidad se vuelven más efímeras, adquieren

\footnotetext{
${ }^{9}$ Recojamos un botón de muestra: "Todo pasajero es una especie de peatón pobre diablo con aspiraciones aristócratas, al entrar en conflicto de pisotones, arrumacos, y empujones con los demás pasajeros, y sobre todo con el chofer que, así se ve convertido en el principal enemigo: ¡Cafre irresponsable! ¡Sordo! ¡Pendejo! Pendeja la suya. ¿Que no ve que no hay parada? ¿Que no oye que le estoy tocando? Si es tan fina, pues cómprese un Cadillac." (Blanco 1988: 120)

${ }^{10}$ Ese prólogo está dedicado a Elena Poniatowska, otra cronista cuya vinculación con la fotografía es notable como demuestra en Luz y luna, las lunitas, Las soldaderas o en obras de colaboración como De fiesta. Celebraciones tradicionales en Chiapas con Raúl Ortega. No se trata de la única obra en la que la prosa de Blanco comparte espacio con la fotografía. En "La campaña socialista en Oaxaca", crónica contenida en Postales trucadas, Blanco incluye textos del libro de la fotógrafa mexicana Lola Álvarez Bravo. Y por supuesto no podemos olvidar Los mexicanos se pintan solos donde la convivencia entre texto e imagen es continua y que se abordará más adelante.
} 
velocidad y se trasforman y esfuman en un parpadeo. Se podría decir de la fotografía como del periodismo: nada hay más viejo que una foto de ayer. (1999: 7)

Como señala Blanco, el espacio urbano aparece irremisiblemente ligado al fluir temporal y por ello huye del estatismo de la fotografía. La crónica busca superar la instantánea y captura el devenir temporal a través de diferentes rincones de la urbe.

En "Mercados sobre ruedas", texto perteneciente a su primer libro de crónicas, el cronista recorre los mercados que se suceden a lo largo de la jornada y retrata el tipo de clientela que acude a cada uno de ellos. La ciudad parece multiplicarse en mil ciudades distintas en función no solo del lugar sino del momento del día. A medida que las horas pasan la vida se irá desplazando y los distintos grupos sociales toman posiciones: la ciudad del obrero no es la misma que la que vive el estudiante, el empresario, la secretaria o el niño que vende chicles en los semáforos.

En otros momentos detiene el foco de su crónica y toma nota de los cambios que experimenta un lugar concreto a lo largo de todo un día como en el texto "Calle de San Juan Letrán", o a lo largo de varios años como sucede en "Avenida Álvaro Obregón" ambas en Función de medianoche. La "crónica del envejecimiento de los edificios", como el autor mismo la llama, se supera en el momento en que retrata algo más que los cambios arquitectónicos y profundiza en el tipo de habitantes de la calle, la mudanza en las costumbres, la vida íntima de la avenida:

Uno podía ensoñar en los tiempos que Ramón López Velarde o Antonieta Rivas Mercado paseaban por la entonces avenida Jalisco, hoy Álvaro Obregón. Pero no, seguramente hoy esta avenida es más calle que nunca, más viva, más ventanera, más contrastada; seguramente los blasones, balaustradas, mamposterías, decoraciones, estructuras no encontraron en su pasado señorial mejores habitantes que su desclasada y bullangera población de hoy. (Blanco 1981: 93)

El paso del tiempo también puede percibirse en el análisis de la sociedad a través de los espacios y monumentos históricos que Blanco realiza en "La Ciudad de México. Aspectos de una modernización", texto contenido en Cuando todas las chamacas se pusieron medias nylon. Comienza con un vistazo a los palacios porfirianos que, abandonados por sus dueños al estallar la Revolución, fueron ocupados por las clases bajas y convertidos en negocios o viviendas. Después traza un recorrido por la historia de la ciudad enumerando sucesivas transformaciones: la industrialización y la llegada del obrero, la evolución de la arquitectura y el arte de masas. Todos estos cambios referidos van construyendo una ciudad llena de lugares como el Zócalo o la basílica de Guadalupe concebidos para acoger a una población que se desborda en cada reunión urbana.

Blanco interroga a los monumentos, a partir de los edificios reflexiona acerca de la historia de una ciudad que concentra el devenir de la nación. Así se puede 
comprobar cuando se refiere al Monumento de la Revolución en la crónica del mismo nombre o al edificio de la Cámara de Diputados en "El teatro de Donceles", ambas contenidas en Función de medianoche. En "En una ciudad tan punk, ¿por qué asombrarse de Bellas Artes?", texto incluido en Un chavo bien helado, el cronista repasa la historia del Palacio de Bellas Artes lo cual le obliga a hablar del Porfiriato, la Revolución y sus primeros gobiernos, la evolución de la clase alta y de los políticos mexicanos.

Cuando Blanco hace memoria y recuerda la inauguración de la plaza del metro Insurgentes repasa las transformaciones que provocó en el área más próxima. Una de ellas tiene que ver con la mudanza del tejido social que experimentó la Zona Rosa:

La glorieta del Metro Insurgentes, por lo demás, democratizó forzosamente esta zona que se pretendía un ghetto de la farándula y el turismo. Nacos get out! Nacos go home! De pronto llegaron por oleadas de cientos y de miles los muchachos desempleados o subempleados de Neza, con sólo bajarse del metro. (De Neza a Niza)" (1990b: 60)

El cronista funde en el texto el pasado y el presente de un lugar que, cuando fue construido, se pretendía un avance del futuro. Precisamente fue el escenario elegido para rodar algunas escenas de la producción estadounidense Total Recall, película ambientada en el año 2084. ${ }^{11}$

Como apunta Boris Muñoz, la memoria funciona como un aparato transhitórico: "para crear el presente real reproduce el pasado y el futuro imaginados" (86) . Devota del dios del tiempo, la crónica es, como la plaza de Insurgentes, el lugar idóneo para la fusión de épocas que representa la ciudad de México: recupera el pasado nunca cancelado de la ciudad, dibuja su presente y ensaya con su escritura la utopía de una urbe futura, más allá del fin apocalíptico que se vive día a día.

En esta ciudad en la que las edades se simultanean Blanco atrapa la sensación vertiginosa de un fluir temporal acelerado vinculándola con la cuestión del consumismo. El consumo imprime velocidad a la metrópoli porque se sirve de la moda, transitoria por definición, y exige una satisfacción permanente e imposible.

En las aldeas la vida se adentra, se concentra, ¿permanece? En la ciudad corre: minutos desbocados como mercancías: aparadores refulgentes de aparatos que ya no estarán mañana: viaductos y periféricos contaminados de automóviles que están dejando de ser del año, que están bajando de precio, que están esperando cambiarse por el modelo del año que ya va a empezar: muchedumbres que están cambiando los pantalones ajustados por holgados como banderas o volviendo a

${ }^{11}$ Esta película dirigida por Paul Verhoeven y protagonizada por Arnold Schwarzenegger se conoció en España con el título de Desafio total. 
los ajustados, con o sin campana, con o sin rasgaduras, con o sin parches o incrustaciones [...]. (Blanco 1990b: 154)

La sucesión de periodos oracionales separados por los dos puntos así como el uso reiterado de perífrasis verbales durativas traslada la sensación de ritmo trepidante al texto. Cada frase se desborda en otra y la lectura se convierte en una actividad tan agotadora como la vida que impone la ciudad del consumo. A menudo la oferta abundante y variadísima que se puede encontrar en la ciudad se refleja en el estilo de Blanco que ocupa entonces periodos largos, enumeraciones interminables en las que se suceden todos los productos y servicios al alcance de la mano para el cliente que tiene dinero y está dispuesto a gastarlo. Podríamos encontrar numerosos ejemplos de este procedimiento en los textos que dedica a los mercados o tianguis, a la venta ambulante y a los centros comerciales.

En Los mexicanos se pintan solos Blanco incluye un texto sobre el céntrico mercado de la Merced: las enumeraciones prolongadas colman el discurso y la prosa se multiplica como los productos que desfilan por delante de los ojos del cliente, sin orden ni concierto, mientras se traslada al texto la multitud en tránsito del mercado. Lugar de abundancia, la Merced desborda las calles que la contienen del mismo modo que el texto se sobrepasa a sí mismo, se excede. En esta profusión la cita escapa necesariamente a la brevedad:

La Merced era el estómago y la caja de caudales de la ciudad, su florería y su zahúrda en una mezcla de aromas y tufos, podredumbres y eclosiones de vida en más de 100 hectáreas con incontables puestos y vendimias (quien quiera contarlos se acercará a la cifra de 10 mil) y más de 1,000 establecimientos formales de almacenes, talleres y tiendas de ropa, telas, boneterías, ferreterías, zapaterías y productos de cuero, jarcierías y dulcerías, aparatos "electrodomésticos", productos de plástico, tlapalerías, expendios de frutos y carnes, yerbas y aparatos eléctricos, cohetes (que estallaron, causando una gran tragedia en el mercado y en los puestos callejeros), verduras y pájaros, jarros y fayuca, todo ello resumido rezumado- en un aroma dulzón con mucho de desagüe, esencias florales y penetrancias de cebolla, que llega hasta los túneles del metro y anuncia la estación sin necesidad de letreros. (49) ${ }^{12}$

${ }^{12}$ La cita remite necesariamente a la recreación del tianguis precolombino que dibuja Alfonso Reyes en Visión de Anáhuac y otros ensayos. Pero aunque el hilo conductor de la tradición es evidente podría subrayarse una diferencia que no es menor: el desorden del mercado actual y su abigarramiento contrasta con el orden y la armonía con el que se organizaban las mercancías en la época en que Cortés llega a Technochtitlan, según recrea Reyes. Este, citando a Cortés escribe: "Cada especie o mercaduría tiene su calle, sin que se consienta confusión. [...] Allí venden - dice Cortés- joyas de oro y plata, de plomo, de latón, de cobre, de estaño; huesos, caracoles y plumas; tal piedra labrada y por labrar; adobes, ladrillos, madera labrada y por labrar. Venden también oro en grano y en polvo, guardado en 
El consumo se impone en la cotidianeidad de la urbe y, con ferocidad creciente, trastorna los hábitos de sus pobladores: el ocio elige como escenario el centro comercial, la publicidad y los escaparates condicionan el paisaje urbano, conforman una ciudad paralela de cuerpos perfectos, mercancías elegantes y sueños de bienestar que a menudo desmiente esa otra ciudad real que corre al trabajo diario.

Si Carlos Monsiváis se refería a la ciudad como un gran tianguis (Bencomo 2002: 132) Blanco elige una metáfora más moderna y cercana a la clase media protagonista de la mayoría de sus crónicas: el gran almacén.

La ciudad es un gran almacén, un interminable proliferar de anuncios, de aparadores, de nombres de establecimientos, de marcas registradas, de gritos de compre, compre, compre. Oferta, ganga, descuento, aproveche; usted es tan maravilloso como las mercancías que puede comprar; renovarse o morir: compre este producto nuevo, compre: su identidad urbana es una tarjeta de crédito.

Se ha descrito a la ciudad moderna como selva, como océano, como monstruo, como enjambre y gusanera. Yo la veo un gran almacén vistoso, rodeado de desiguales fraccionamientos clasemedieros y grandes extensiones de lodazales proletarios; y por ahí, escondidos tras murallas urbanísticas de viaductos y periféricos -como otrora, sobre los montes, los palacios de cuentos de hadas-, las zonas del privilegio. (1988a: 28)

Desde sus primeras colecciones de crónicas, Función de medianoche y Cuando todas las chamacas se pusieron medias nylon, Blanco ha visto en el capital la fuerza principal que violenta el espacio urbano. El dinero transforma el aspecto físico de la ciudad y la convierte en territorio para ciudadanos motorizados donde el espacio público efectivo desaparece en favor de carreteras y lugares dedicados al consumo. Se trata de un proceso que se hace visible en diferentes partes de la ciudad. Así lo relata en "Crónica de Coyoacán" o en "Panorama bajo el puente". En esta última reflexiona a partir del ejemplo de Tacubaya sobre la disposición urbana cumple una función de segregación según la cual una población privilegiada puede moverse rápida y cómodamente en sus automóviles mientras otro grupo social se mantiene en los márgenes asediado por los pasos a nivel, los túneles y las alambradas. Se impone así una ciudad hecha para el dinero y por el dinero, que olvida al ciudadano y se convierte en un encierro para quien no tiene pesos para comprarla. ${ }^{13}$

cañutos de pluma que, con las semillas más generales, sirven de moneda. Hay calles para la caza, donde se encuentran todas las aves que congrega la variedad de los climas mexicanos, tales como perdices y codornices, gallinas, lavancos, dorales, zarcetas, tórtolas, palomas y pajaritos en cañuela; buharros y papagayos, halcones, águilas, cernícalos, gavilanes". (19)

${ }^{13}$ De acuerdo con esta idea, en "Panteras de la ciudad" Blanco escribe: "En la jaula urbana el hombre es la pantera que sabe que hay praderas y montañas; y si no lo supiera, la 
Frente a esta ciudad inhumana la crónica contemporánea mexicana busca rescatar a la multitud que la habita. Una ciudad superpoblada como el Distrito Federal sugiere la pesadilla de un exceso demográfico imposible de calcular pero, para Blanco, "El principal panorama de la ciudad es su gente" (1990b: 9). ${ }^{14}$ De esa población afirmará: "decir solamente que se amontona es no quererla mirar más que amontonada: no, la muchedumbre es también fluida y enérgica en las múltiples y rápidas corrientes diferenciadas que pueblan el día urbano" (9). Apunta así una de las características de la multitud como "sujeto migrante" que Bencomo señala: "La multitud se desplaza constantemente señalando nuevos espacios, nuevas residencias" (2003: 194).

El concepto de multitud se intercambia en ocasiones con otro del que es heredero: la idea de sociedad civil usada anteriormente por cronistas como Carlos Monsiváis y Elena Poniatowska. Anadeli Bencomo vincula la sociedad civil con la megalópolis y prefiere la idea de multitud para referirse a los habitantes de la postmegalópolis (2003: 186). En definitiva, la multitud que retrata Blanco se corresponde con la noción que manejan Antonio Negri y Michael Hardt en su obra Imperio entendida como entidad heterogénea, activa y creadora de prácticas democráticas aunque no reductible a una unidad política.

La crónica de Blanco participa de dos posturas ante esa multitud. Por un lado reconoce en ella la posibilidad de realizar algunas propuestas democratizadoras y, por otro critica, sus "comportamientos seriados, imaginarios compartidos y manipulados, consumos programados, etc" (Bencomo 2003: 195).

En Función de medianoche Blanco evidencia una actitud favorable hacia la clase trabajadora a la que ensalza por considerarla resistente a la penetración de la nueva modernidad acrítica y basada en el consumo. Durante los años setenta la tendencia gramsciana dentro de los estudios sobre cultura popular insistía en ver ciertos

televisión o el cine insistirían en recordarle, con los más apetitosos resultados de la técnica, los reinos que no fueron para él” (1990b: 65) y añade un poco más adelante: “¿De qué sirve que el orbe sea infinito si el salario no lo es; si uno gana tanto, tiene que sufrir a mengano y a zutano, pagar tal cantidad de renta, atenerse a tales y cuales rutinas y obligaciones, y en fin, sobrevivir en los límites precisos de la jaula que le ha dado la suerte?" (66).

${ }^{14}$ No solo Blanco habla de la multitud. Hermann Bellinghausen le dedica todo un libro, Crónica de multitudes, donde la retrata en el espacio público: en el desfile del primero de mayo, en el aniversario de la Revolución, en una jornada electoral, en un concierto, en las horas posteriores al temblor de 1985. En la multitud encuentra Bellinghausen la razón de que la ciudad desastre siga siendo amada y, en cierta manera, amable: "Sus calles son habitadas todavía por gente maravillosa, llena de magia y trucos, desconfiada, amenazante a veces, cercana entre sí, una muchedumbre espléndida y rabiosa, tan insuficientemente horrible como la ciudad (calles, espacios) que nos cobija a todos por igual [...] Cuando la gente sale a defenderla se apodera de ella. Aunque esté cansada y vieja, nos pertenece todavía" (166). 
aspectos de esta como resistencia contra la hegemonía cultural. Si, como mantiene Foucault, el poder no se ejerce solamente de modo unidireccional desde arriba hacia abajo sino que se distribuye de manera reticular, no es descabellado pensar que esa red implique puntos de los sectores llamados populares. Pero años más tarde, en los textos que componen el segundo libro de crónicas de Blanco, estas notas de optimismo respecto a las clases populares comienzan a desaparecer. ${ }^{15} \mathrm{El}$ consumismo ha calado en todos los niveles de la sociedad:

Después de escupir llamas, el niño se comprará unos chicles con sabor toronja con estrellas, y no un huevo. Ni modo que se arriesgara a desfigurarse todavía más por un pinche taco; quiere dignidad, y la dignidad urbana se da exclusivamente con el bienestar, y el bienestar es mercancías industrializadas. (Blanco 1988: 27) ${ }^{16}$

Subrayando la importancia de la multitud como colectivo, José Joaquín Blanco no se detiene tanto en las individualidades sino más bien en la energía vital que genera al ocupar los espacios públicos y que la diferencia de la masa, más pasiva y susceptible de ser manipulada (Bencomo 2002: 150). ${ }^{17}$ Cuando Blanco se detiene en

${ }^{15}$ Aún pueden encontrarse en Cuando las todas las chamacas se pusieron medias nylon ciertos resquicios de confianza en la resistencia cultural ejercida por las clases populares, confianza que a partir de los años 90 desaparece de manera definitiva: "Varios autores han expuesto cómo la pretendida "incultura" de overol es la única cultura que realmente funciona positivamente en nuestras ciudades, y que gracias a esa resistencia popular a la catástrofe del desorden burocrático y empresarial, se entorpece, retarda o distrae en algunos aspectos la política de desastre nacional, permitiendo cierto respiro. Son masas que a fin de cuentas diariamente modifican en algo el desastre, para sobrevivir lo mejor posible" (Blanco 1988: 44).

${ }^{16}$ Frente a las teorías neogramscianas que reconocen iniciativa y poder de resistencia en la cultura popular, los reproductivistas entienden la cultura como un único bien del cual las clases se apropian de manera desigual. El argentino Néstor García Canclini, propone, sintetizando: "En naciones multiétnicas, pluriculturales, como las latinoamericanas, podemos argumentar que no existe tal unificación cultural, ni clases dominantes tan eficaces para eliminar las diferencias o subordinarlas enteramente. Pero esta crítica no elimina la fecundidad demostrada por los análisis reproductivistas para explicar porqué los comportamientos de las clases populares no son muchas veces de resistencia e impugnación sino adaptativos a un sistema que los incluye" (1990: 254). José Joaquín Blanco se coloca en la posición que García Canclini subraya: hay una cultura popular crítica que podría ser instrumento de lucha y resistencia pero que, si no se ejerce como tal, no es más que la repetición disminuida de los hábitos de la élite.

${ }^{17}$ Anadeli Bencomo también diferencia el concepto "pueblo", que exige una identidad nacional que lo cohesione, del de "multitud" que "apunta a la multiplicidad de identidades" (2002: 150). El pueblo así definido parece estar ausente de la crónica y de la ciudad moderna, consecuencia quizá de la erosión de esa identidad nacional. Blanco lo constata 
algunos personajes urbanos lo hace con una tendencia más o menos acusada a caracterizarlos como tipos: la prostituta en el México del siglo XIX o el chófer y el pistolero a principios del siglo XX. Ya en el DF actual nos topamos con los mendigos a los que dedica la crónica "Mendigos secretos" en Los mexicanos se pintan solos pero también con los cuidacoches, las secretarias, las criadas o con el "chavo helado", caracterización de un tipo que resume en su figura los rasgos de la época. ${ }^{18}$

Parecería que la individualidad va desapareciendo en beneficio de una presencia que lo ocupa todo, un personaje principal que se hace con todas las tramas: la ciudad, sobre todo aquella donde se mueve y sueña la clase media. En "La ciudad enemiga" Blanco llega a negar la posible intimidad del habitante urbano: "ningún examen de conciencia puede ser íntimo, como si el individuo fuera un ser independiente, sino exterior; y todos los problemas del citadino se reducen al de su adaptación o inadecuación al modelo de vida de la ciudad" (1981: 58). Toda crónica de la ciudad, aunque sea vivida desde la subjetividad, se convierte así en sociología. Parecería que, víctimas de un extraño proceso "los citadinos van teniendo menos personalidad y más -¿cómo decirlo?- "citadineidad"." (57).

Paradójicamente, al tiempo que esto sucede la ciudad se va humanizando: se convierte en un cuerpo aquejado por dolores, surcado por cicatrices. La ciudad tiene su personalidad, es "malencaradita" (1993: 31), tiene sus odios y sus debilidades. Blanco la trata de tú a tú, la interroga y la increpa, pero también la acaricia con sus palabras, le dedica páginas interminables porque sabe que no hay otra, temible y dañina, pero suya y reconocible: "Mamasota fea y terrible — si se quiere-, pero madre que no discrimina, la capital" (30). Madrastra obligada, la ciudad de México arrastra a la mayoría de edad al joven, es maestra de la vida, aceleradora de vocaciones, reto diario para el que la habita.

Finalmente lo que salva esta ciudad con la que los cronistas mantienen una relación bipolar, un amor-odio al que dedican muchas páginas para explicárselo, es la identificación del escritor con la urbe. Al final de "En una ciudad tan punk, ¿por qué asombrarse de Bellas Artes?" Blanco acaba identificándose con cada uno de los edificios emblemáticos de la ciudad, asume como propio el pasado oscuro de la catedral o el aspecto ostentoso del Palacio de Bellas Artes.

precisamente durante las fiestas patrias: "tal vez, insinuar que el pueblo ya no es el pueblo, que el pueblo se ha quedado sin pueblo, que ha sido desplazado y sustituido por una alegoría edificante del pueblo" (1990a: 106).

${ }^{18}$ El "chavo helado" no es un personaje exclusivo de Blanco. Fabrizio Mejía Madrid se detiene en él en su texto "Insurgentes" recogido en la antología de Rubén Gallo. La coincidencia refleja la presencia de un tipo social que acaba por convertirse en símbolo de una época. 
Uno empieza a amarlo, a reconocerlo, a reconciliarse con él, como hemos hecho ya las paces con la catedral — edificio mucho más caro, mucho más tardado y con más turbia historia-; con las fuentes de la Alameda, con el chatote Palacio Nacional; con las estatuas de Reforma, y la verdad, hasta con la Glorieta del Metro (Insurgentes). Porque hasta en sus fealdades -o más elocuentemente en sus fealdades - la ciudad refleja a sus habitantes. (1990a: 47)

Frente a la identidad urbana marcada por el consumo que elimina vínculos locales en favor de una identidad trasnacional y deja al nacionalismo relegado a pantomima estatal o espectáculo televisivo, ${ }^{19}$ Blanco opone otro tipo de cultura urbana creada desde las bases de la multitud. Se trata de una nueva identidad no dictada por el gobierno ni por los medios de comunicación, configurada por agrupaciones cívicas a nivel local en la línea que apuntan los ya mencionados Negri y Hardt. ${ }^{20}$ Así lo explicita en "La ciudad enemiga": "La gran liberación sería, desde luego, la existencia de sindicatos, partidos políticos, agrupaciones o clubes independientes, que fueran creando gregariamente modos de vida urbana opuestos a los de la Ciudad Dominante" (Blanco 1981: 59). Estos nuevos modos de vida perforarían la masa aplastante de la ciudad capitalista creando dentro de ella canales de comunicación. El cronista apuesta por "otra" cultura, popular, urbana y crítica que será, precisamente, la nueva identidad que defiende la crónica.

La escritura se convertirá en una forma más de trazar esos conductos de respiración. La prosa de Blanco se pretende liberadora y desobediente. Los juegos de palabras que trastocan el sentido y acercan el discurso al absurdo apuntan no tanto a la carcajada como a la desautomatización del lenguaje común. El refrán que

19 En el prólogo a Cuando todas las chamacas se pusieron medias nylon titulado precisamente "Identidad nacional y cultura urbana" Blanco escribe: "Una característica fundamental de la cultura urbana es la de convencer a la persona que tiene poder, prestancia, dominio, belleza y vigor solamente a través de su función de consumidor" (25). El consumo como generador de nuevas identitades está en la base de las ideas que desarrolla Néstor García Canclini en Consumidores y ciudadanos: la identificación del individuo se produce con grupos a los que se vincula gracias a sus hábitos de consumo.

${ }^{20}$ En su obra Imperio, Negri y Hardt escriben: "Las fuerzas creativas de la multitud que sostienen el imperio también son capaces de construir autónomamente un contraimperio, una organización política alternativa a los flujos e intercambios globales. Las luchas por combatir y subvertir el imperio, así como aquellas destinadas a construir una alternativa real deberán pues librarse en el terreno imperial mismo — en realidad, estas nuevas luchas ya han comenzado a surgir - . A través de estas contiendas y muchas otras semejantes, la multitud tendrá que inventar nuevas formas democráticas y un nuevo poder constitutivo que algún día nos conduzca a través del imperio y nos permita superar su dominio" (16-17). 
se resuelve novedosamente o los continuos trastocamientos de frases hechas obligan al lector a permanecer alerta, y a no dar nada por supuesto. ${ }^{21}$

El discurso de Blanco admite voces disparatadas que se preguntan y se increpan. Amplía la variedad de timbres contenidos convirtiéndose en una prosa multitudinaria que, a pesar de provenir de una personalidad cronística muy marcada, no excluye la pluralidad. Un ejemplo lo hallamos en "Algo de cruz y de calvario", texto de Un chavo bien helado, donde, a pocas líneas del inicio, la prosa toma estos rumbos:

Pero vamos a la otra preguntota: ¿Por qué nosotros, mexicanazos como siempre, escribimos México con la equis - que algo tiene de cruz y de calvario, o que la llevamos en la frente, como no ha faltado quien poetice-, y no con la jota española de academia y pandereta? Los gachupines y los latinoamericanos cultos (o "chultos": neologismo de Luis Zapata) no dejan de joder con el jacarandoso jitanjafórico Méjico de la jota. Pero nosotros dale que dale con la equis. "¡Eso no es español!”, exclaman. “¿De dónde sacaron su famosa equis?”.

—iDel francés, naturalmente! — responde Pero Grullo—. Le Mexique!

Gertrude Stein: México-es-México-es... O bien: México-se-escribe-con-equisporque-se-escribe-con-equis-lo-que-escrito-con-equis-está." (114)

A menudo los dobles sentidos o los juegos de palabras se relacionan con temas como el sexo y lo escatológico. Más allá de la intención escandalizadora parece que la escritura busca atentar contra tabúes y eufemismos. Blanco no evita la alusión directa o el chiste callejero e incorpora palabras cajón de sastre y groserías. Su trabajo pretende construir una lengua diferenciadora, no anquilosada sino creativa: "La sociedad no tiene por qué hablar con la Voz del Amo: sufrirla ya es bastante martirio; debe hacerse de su propia voz, e incluso diferenciarse de aquella" (1990a: 28). La razón, para él, está clara: "Es más difícil oprimir o vender con un idioma libre que con un idioma policíacamente reglamentado" (28).

Consciente de que el lenguaje transmite siempre un contenido político y social, Blanco concede especial atención a ciertas palabras ("transar" en "Elogio de la transa" o "especular" en "La comunidad de los justos", donde bucea en la relación que subyace entre economía y religión), a través de las cuales reflexiona sobre la

21 La prosa de Blanco admite palabras en inglés, coloquialismos, fragmentos de canciones populares y neologismos: "Cada quien muy su rollo y todo peace-and-love, vámonos-recio y muy chévere.

¡Un, dos y tres, qué paso tan chévere! ¿Qué paso tan chévere!

Bailando solo, yo me entiendo: No voy en tren / voy en avión/ no necesito a nadie: a nadie alrededor...

Al bailar nadie debe recordar que tiene barriga o piernas chuecas o que está de plano muy chaparro, muy barroso o muy-monstruo-de-la-laguna-negra." (1990b: 29) 
sociedad que las crea y las utiliza. Estos textos que comienzan como una reflexión sobre el lenguaje superan esa misión para adentrarse en el análisis de la sociedad urbana que lo utiliza. En una actividad que tiene algo de freudiana Blanco está atento a las palabras que permiten evidenciar los conflictos internos de la sociedad que se observa.

La prosa liberadora que ensaya Blanco tiene que ver entonces con una intención de apertura de espacios, de creación de zonas de expresión. La escritura provee el mínimo oxígeno necesario para vivir, se convierte en el clavo ardiendo que permite seguir dando lucha. El periodismo crítico es el modo en que el cronista se instala en la ciudad, su campo de acción:

La literatura y el periodismo independiente, tan vitales y difíciles de crear y conservar, no quitan la soga del pescuezo: permiten gritar, respirar un poco entre la asfixia totalizadora, rescatar algunos datos verdaderos entre el cenagal de mentiras e infamias derramado en diluvios constantes; recobrar perfiles de utopías, no olvidar la dignidad más esencial e íntima: asomarse a la realidad concreta entre tanta ilusión manipulada, y hasta ser -en casos cumbres-, durante unos minutos, tan inteligentes y amplios como necesitamos serlo cotidianamente. (1981: 52)

A pesar de las limitaciones, la labor del cronista resulta imprescindible para la conciencia cívica del ciudadano tal y como se concibe sobre todo a partir de finales de los sesenta. Las crónicas de Elena Poniatowska y Carlos Monsiváis escritas en esa década encuentran en Función de medianoche una continuidad tanto en el tema como en el espíritu cívico que las sustenta.

A partir de ese primer libro de crónicas, la crítica social de Blanco evoluciona con un progresivo abandono de la anécdota, la escena o el tema concreto hacia un análisis más general. En Función de medianoche y Cuando todas las chamacas se pusieron medias nylon Blanco dedica sus crónicas a aspectos locales y ligados a la vida cotidiana de la Ciudad de México ("Impuesto ¡manos arriba!", "Caminantes sin banqueta", "La UNAM en la política"). En Un chavo bien helado (1990) seguirá ocupándose de problemas locales pero con un uso creciente del estereotipo y del personaje ficcionalizado que aleja la crítica de la inmediatez social. En el mismo año publica Los mexicanos se pintan solos. Esta coincidencia ilustra los dos modos en que Blanco se acerca a la realidad urbana: la crítica y el costumbrismo. ${ }^{22}$

\footnotetext{
${ }^{22}$ Anadeli Bencomo subraya la distancia entre Función de medianoche y Los mexicanos se pintan solos. Según ella este último libro "adolece de un vouyerismo complaciente que dista del tono escéptico de las primeras crónicas del autor. Las fotografías que acompañan al texto caen de lado de la ilustración hedonista, de la imagen celebradora de una ciudad desbordada por las multitudes urbanas" (2002: 196).
} 
Los mexicanos se pintan solos es una obra orientada a la pintura de ambientes y el retrato de gentes a la manera de aquellos libros de textos costumbristas que siguen la estela iniciada por obras como Les français peints par eux-mêmes, y sobre todo la organización y selección de tipos de Los españoles pintados por sí mismos. En 1854 se publica en México Los mexicanos pintados por sí mismos. Como este, el libro de Blanco mezcla texto e imagen aunque lo que en aquel fue litografía ahora se convierte en imagen fotográfica.

La escritura de Blanco se acerca en esta obra al costumbrismo tradicional que ponía el acento en la representación de los tipos que configuran el carácter nacional. La crítica social deja paso a un fresco de la ciudad de México que no esconde las miserias pero que tampoco investiga su explicación. ${ }^{23} \mathrm{~A}$ pesar de ciertas notas críticas (las referentes al pueblo de Chimalhuacán y los alrededores del lago de Texcoco afectados por la mala gestión, al uso comercial que los medios de comunicación hacen de las tradiciones o al protagonismo absorbente de la televisión en la vida de los capitalinos con menos recursos) predomina el retrato amable y una actitud menos agria que en libros anteriores.

En Se visten novias (somos insuperables) la crítica se generaliza para referirse sobre todo al espíritu de una época: Blanco arremete contra la ideología imperante durante los años ochenta, dominados por el miedo y las prohibiciones, las ansias de poder basado en el dinero y la capacidad de consumo. En Álbum de pesadillas mexicanas el hecho concreto regresa a las páginas de Blanco aunque no de forma tan evidente como en sus primeras crónicas. La carga crítica ha disminuido y lo seguirá haciendo en Postales trucadas (2005). Se atenúa la virulencia de la crítica al tiempo que se acentúan los recursos humorísticos y absurdos. El resultado es una reflexión más escéptica y resignada que la de sus primeros libros donde el cronista guarda aún ciertas esperanzas en la sociedad civil y sus posibilidades de cambio. Blanco abandona el ataque directo para convertir a la crónica en un espacio de reflexión compartida.

En línea con esta cualidad espacial de la escritura, la crónica de Blanco trata de reconquistar aquellos ámbitos que han sido usurpados a la sociedad civil y reivindica la liberación de lo que considera territorio de resistencia por excelencia: nuestro propio cuerpo. Esta labor que podría pensarse individualista se conecta

${ }^{23}$ Al referirse a la literatura costumbrista de la Francia del Segundo Imperio, Walter Benjamin habla de "literatura panorámica" (1998: 49). Relaciona el incipiente costumbrismo con la pintura de panoramas que pudo observarse en grandes ciudades como París, Londres, Nueva York o Berlín cuya representación significó su mayor esplendor.

Los textos costumbristas recogen a diversos personajes y escenas y se presentan a sí mismos como instantáneas en las que la vista se detiene: “A un primer plano más o menos detallado, plásticamente elaborado, le corresponde un revestimiento, folletinesco y nítidamente perfilado, de análisis social, que proporciona aquí el fondo de la escena, como en el diorama el paisaje" (2005: 545). 
socialmente de manera inequívoca: la auténtica liberación de la mente y el cuerpo no puede entenderse sino como una tarea colectiva. ${ }^{24}$

El control de la inteligencia y de la sexualidad nos obliga a vivir por debajo de nuestras posibilidades. A través de su prosa torrencial el cronista arremete contra esta actitud apocada y reivindica la necesidad de expandir nuestras capacidades: realizarnos en la plenitud sexual e intelectual.

El sexo es nuestra crucifixión, decía D. H. Lawrence; también la inteligencia. Para que las personas sean más utilizables, laboral y políticamente, hay que convertirles el cuerpo -el sexo, la mente- en otra cosa: una sociedad de inteligentes y de buenos amantes sería necesariamente una sociedad de rebeldes; en una sociedad estable y civilizada, en cambio, una persona apenas ejerce y mal las más de las veces (díganlo si no los confidentes de los amantes) su energía amorosa; y su fuerza mental (díganlo si no los pacientes lectores). (1981: 117)

La sexualidad y el ejercicio de la inteligencia son para Blanco actos fecundos que solo pueden manifestarse como tales en un entorno que permita la realización plena del individuo como creador. Por el contrario, una sociedad que nos imprime la característica de consumidores, trata ambos aspectos como mercancías que poseer o como medios de ejercer el poder y los fomenta mientras no supongan un desafío.

Al entender el cuerpo y la mente como espacios sociales, la sexualidad, cuestión íntima donde las haya, se convierte para el cronista en un asunto político. De este modo afirma tajantemente en Función de medianoche : "Más allá de banderas y de partidos, el erotismo individual revela una verdadera posición política. Y en el amor uno actúa políticamente, con transas, generosidades y masacres; ahí actúa cotidiana y corporalmente todo el arsenal ideológico de una sociedad" (71). Siguiendo esta idea, en "Los apetecibles cuerpos de la miseria" en el mismo libro, Blanco lleva las relaciones sociales a la cama: en el sexo se reproduce el contexto social. Una sociedad desigual y opresiva genera relaciones íntimas donde los roles se reparten entre opresor y víctima.

Dentro de esta concepción del cuerpo como espacio político asuntos como el aborto o la homosexualidad cobran una nueva dimensión. A la homosexualidad Blanco dedica, además de algunas crónicas, las novelas Las púberes canéforas o

${ }^{24}$ La labor del cronista como intelectual también debe darse como parte de esa labor colectiva: "El intelectual resulta, en oposición al tradicional culto de la personalidad y la actividad mental glamurosos, un solitario tan desarmado e inorgánico como cualquier otro miembro de la muchedumbre nerviosa del Metro. De ahí que el fortalecimiento de las "estructuras desde abajo" (principalmente la sindical, pero también todas las asociaciones inimaginables, en concordancia con la múltiple realidad de las personas;) sea la condición sine qua non de una práctica realmente cultural" (Blanco 1988: 132). 
Mátame y verás que se inscriben en el tipo de literatura inaugurado en 1979 por Luis Zapata con Las aventuras, desventuras y sueños de Adonis García, el vampiro de la colonia Roma. Conviene subrayar además su interés por el tratamiento que el tema gay ha recibido a lo largo de la historia de la literatura. A partir de las obras de Genet o Verlaine, por citar algunos, a las que dedica sus ensayos, el cronista rastrea la evolución de los tópicos, costumbres y prejuicios que han acompañado a la homosexualidad y su reflejo en el arte. ${ }^{25}$

En "Zona Rosa", incluido en Los mexicanos se pintan solos, el cronista aprovecha la descripción de este barrio para hacer una crónica sobre la evolución de la vida gay en la capital. Pero la pintura del ambiente gay capitalino es más completa en "Sueño de una tarde en la Zona Rosa", crónica contenida en Postales trucadas, donde Blanco hace un recorrido desde los años setenta en el que presta atención a $E l 9$, bar de moda, los abusos policiales, el caos posterior al temblor del 85 y la creciente libertad que impera desde entonces. ${ }^{26}$ Incluye además anécdotas personales y referencias a presonajes conocidos de la cultura mexicana.

Desde la misma primera persona había escrito ya uno de sus primeros textos acerca de la vida gay en la Ciudad de México. "Ojos que da pánico soñar" cierra Función de medianoche y abre la polémica. Blanco habla aquí de los homosexuales de clase media, no de los "homosexuales en la miseria". Las realidades de cada uno de estos grupos son absolutamente diferentes porque "la homosexualidad no tiene esencia, sino historia" (183). La problemática social para Blanco responde a circunstancias sociales que, como tales, son históricas por lo que centra sus críticas y reflexiones en la clase media a la que pertenece. ${ }^{27}$ La intimidad es la puerta de entrada al tema: desde el inicio el cronista se sitúa en el centro del escenario. ${ }^{28} \mathrm{La}$

${ }^{25}$ Estas referencias a la homosexualidad en el arte aparecen en ensayos como "Flaubert y los gays" en Se visten novias (somos insuperables) o "Verlaine: el tañido del olifante", "Feos atributos" y "Genet para principiantes" en Pastor y ninfa.

${ }^{26}$ Blanco constata que tras el temblor "con el caos citadino y el incremento de la corrupción policiaca, se abrieron antros gay por todas partes, especialmente en el centro" (2005: 86) y añade "En una sola generación, y más a causa del desorden gubernamental y de la eficaz corrupción policiaca que de sesudas teorías de liberación gay, todo ello impulsado desde luego por los jóvenes de la explosión demográfica, y teñido de su desempleo, su desencanto y su miseria, se abatieron las murallas del pudor" (87).

27 "No me atrevo a hablar de la homosexualidad en la miseria. Somos tan poca cosa frente a ella: esos homosexuales de barrio, jodidos por el desempleo, el subsalario, la desnutrición, la insalubridad, la brutal expoliación en que viven todos los que no pueden comprar garantía civil alguna; y que además son el blanco del rencor de su propia clase, que en ellos desfoga las agresiones que no puede dirigir contra los verdaderos culpables de la miseria" (Blanco 1981: 184).

28 "Mientras me embrollo con las ideas que trataré de desarrollar en este artículo, paseo por el Parque México mirando a los muchachos que me gustan con esa peculiar "mirada de 
primera persona tanto del plural como del singular se usa aquí con una clara intencionalidad política. Lo personal adquiere dimensión pública:

Sólo me preocupa exponer algunos puntos de vista sobre su historia actual en la ciudad de México, porque conviene discutirla públicamente y no sólo en la nota roja, los chismes y chistes privados; y exponerla personalmente, pues la única forma de romper la presión social abrumadora es enfrentarla individualmente en los ámbitos personales, aun corriendo los riesgos domésticos del llanto de mamá, las sesgadas sonrisitas en la oficina, las desconsoladas discusiones de familia y hasta la díscola alegría de algún rival profesional o un primo envidioso. (184)

Los adjetivos que el cronista adjudica a las miradas homosexuales dicen menos de ellas que del modo en que el resto de la sociedad las percibe: "sesgadas, fijas, lujuriosas, sentimentales, socarronas, rehuyentes, ansiosas, rebeldes, serviles, irónicas, etcétera" (183). Los "ojos que da pánico soñar" hablan más del miedo del que los sueña, desenmascaran lo perturbadora que puede resultar la diferencia. La posición marginal a la que el sistema ha relegado a los homosexuales durante mucho tiempo les ha enfrentado a la sociedad y podría ser aprovechada para ejercer una resistencia a la asimilación, para reivindicar la multiplicidad social frente a la tendencia a la homogeneización. ${ }^{29}$ Pero Blanco advierte ya en este texto algo que con el tiempo confirmaría: los homosexuales de clase media dejarán de ser marginados en la medida en que son descubiertos como potenciales consumidores y se incorporan al sistema que antes les apartaba: "Nos habrán de privilegiar porque tolerarnos será un acceso a nuestros bolsillos. Nuestros ojos no causarán pánico, sino la amabilidad de que "el cliente siempre tiene la razón"." (188). Más que contra la represión violenta y física, fácilmente identificable, Blanco alerta contra otra represión de la sexualidad profunda: la que impone el mercado banalizando nuestra intimidad.

La crónica de Blanco proporciona en primer lugar un espacio de visibilidad, aprovechando la experiencia personal, para una temática que empieza a salir a la luz. A partir de ahí podrá darse la reflexión y el análisis. Esta apertura de espacios forma parte de su proceso para humanizar el tiempo veloz y mercantil de la urbe y

puto" cuya escandalizada descripción sería insuperable para escribir un artículo amarillista." (Blanco 1981: 183)

${ }^{29}$ La vinculación entre lo personal y lo político a la que anteriormente nos referíamos es formulada por Blanco de manera específica en este texto: "Mi tesis, aun bastante vaga, es que los homosexuales mexicanos de hoy -no necesariamente los de ayer ni los de mañana-, al sufrir las persecuciones, represiones, discriminaciones del sistema intolerante, necesariamente estamos viviendo una marginalidad que además de su joda tiene sus beneficios: los valientes beneficios del rebelde, que no son intrínsecos a opción sexual alguna sino a una opción política" (1981: 185). 
reconstruir su espacio desmesurado: se trata de hacer de la ciudad un lugar habitable. La crónica cumple así con una de las promesas de la literatura: ser un modo de conocimiento íntimo del mundo al tiempo que ejerce una voluntad de cambio sobre él.

\section{BIBLIOGRAFÍA}

BARTHES, Roland.

1967 El grado cero de la escritura. Buenos Aires: Jorge Álvarez.

BELLINGHAUSEN, Hermann.

1987 Crónica de multitudes. México: Grijalbo.

BENCOMO, Anadeli.

2002 Voces y voceros de la megalópolis. La crónica periodísticoliteraria en México. Madrid/Frankfurt: Iberoamericana/Vervuet.

2003 "La rebelión de la multitud: nuevas fuerzas urbanas", en MUÑOZ, Boris y Silvia Spitta (eds.), Más allá de la ciudad letrada: crónicas $y$ espacios urbanos. Pittsburg: Instituto Internacional de Literatura Iberoamericana, Universidad de Pittsburgh, pp. 185-205.

BENJAMIN, Walter.

1998 Poesía y capitalismo. Iluminaciones II. Madrid: Taurus.

2005 El libro de los pasajes. Rolf Tiedemann (ed.), Luis Fernández Castañeda, Isidro Herrera y Fernando Guerrero, trad. Madrid: Akal.

BLANCO, José Joaquín.

1981 Función de medianoche. Ensayos de literatura cotidiana. México: Era.

1988 Cuando todas las chamacas se pusieron medias de nylon (y otras crónicas). México: Juan Boldó i Clement Editores, Enjambre.

1990a Un chavo bien helado. México: Era.

1990b Los mexicanos se pintan solos. Crónica, paisajes, personajes de la Ciudad de México. México: Ciudad de México Librería y Editora.

1993 Se visten novias (somos insuperables) y otras crónicas. México: Cal $\mathrm{y}$ arena.

1998 Pastor y ninfa. Ensayos de literatura moderna. México, cal y arena.

1999 Ciudad de México. Espejos del siglo XX. México: ConaCulta, INAH, Era.

2002 Álbum de pesadillas mexicanas. México: Era.

2005 Postales trucadas. México: Cal y arena.

DELEUZE, Gilles y Felix GUATTARI.

2003 Rizoma (Introducción). José Vázquez Pérez y Umbelina Larracleta, trad. Valencia: Pre-Textos. 
GALLO, Rubén (ed.).

2005 México DF: Lecturas para paseantes. Madrid: Turner.

FOUCAULT, Michel.

1992 La microfísica del poder. Julia Varela y Fernando Álvarez-Uría, eds. y trads. Madrid: La Piqueta.

GARCÍA CANCLINI, Néstor.

1990 Culturas híbridas, estrategias para entrar y salir de la modernidad. México: Grijalbo.

1995 Consumidores y ciudadanos. Conflictos multiculturales de la globalización. México: Grijalbo.

HARDT, Michael y Antonio NEGRI.

2002 Imperio. Trad. de Alcira Bixio. Barcelona: Paidós.

MonsIVÁIs, Carlos.

2006 A ustedes les consta. $2^{\mathrm{a}}$ edición corregida y ampliada. México: Era. Mũ̃oZ, Boris.

2003 "La ciudad de México en la imaginación apocalíptica", en Boris Muñoz y Silvia Spitta (eds.), Más allá de la ciudad letrada: crónicas y espacios urbanos. Pittsburg: Instituto Internacional de

REYES, Alfonso. Literatura Iberoamericana, Universidad de Pittsburgh, págs. 75-98.

2004 Visión de Anáhuac y otros ensayos. México: FCE.

SALAZAR, Jezreel.

2006 La ciudad como texto. La crónica urbana de Carlos Monsiváis. Monterrey, Nuevo León: Universidad Autónoma de Nuevo León.

SPITTA, Silvia

2003 "Prefacio. Más allá de la ciudad letrada" en Boris Muñoz y Silvia Spitta (eds.), Más allá de la ciudad letrada: crónicas y espacios urbanos. Pittsburg: Instituto Internacional de Literatura Iberoamericana, Universidad de Pittsburgh, págs. 7-23.

VILLORO, Juan.

2006 El eterno retorno a la mujer barbuda / El viaje a México. Adolfo Castañón. Caracas: Fundación para la Cultura Urbana. 